\title{
Offensive Behavior, Striatal Glutamate Metabolites, and Limbic-Hypothalamic-Pituitary-Adrenal Responses to Stress in Chronic Anxiety
}

Enrico Ullmann ${ }^{1,2,3, *} \mathbb{C}$, George Chrousos ${ }^{3,4} \oplus$, Seth W. Perry ${ }^{5}$, Ma-Li Wong ${ }^{5}$, Julio Licinio ${ }^{5}$, Stefan R. Bornstein ${ }^{2,6}$, Olga Tseilikman ${ }^{3,7}$, Maria Komelkova ${ }^{3}{ }^{(1)}$, Maxim S. Lapshin ${ }^{3}$, Maryia Vasilyeva ${ }^{3}$, Evgenii Zavjalov ${ }^{8}$, Oleg Shevelev ${ }^{8}$, Nikita Khotskin ${ }^{8}$, Galina Koncevaya ${ }^{8}$,

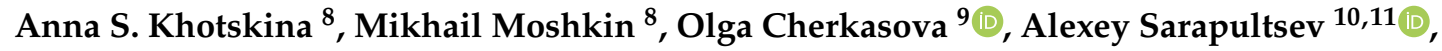
Roman Ibragimov ${ }^{10,11}$, Igor Kritsky ${ }^{10,11}$, Jörg M. Fegert ${ }^{12}$, Vadim Tseilikman ${ }^{3}$ and Rachel Yehuda ${ }^{13}$

1 Department of Pediatric Psychiatry, Psychotherapy and Psychosomatics, University of Leipzig, 04107 Leipzig, Germany

2 Department of Medicine, Technical University of Dresden, 01309 Dresden, Germany; stefan.bornstein@uniklinikum-dresden.de

3 School of Medical Biology, South Ural State University, 454080 Chelyabinsk, Russia; chrousos@gmail.com (G.C.); diol2008@yandex.ru (O.T.); mkomelkova@mail.ru (M.K.); lapshin1982@yandex.ru (M.S.L.); carin-shik@mail.ru (M.V.); vadimed@yandex.ru (V.T.)

4 University Research Institute of Maternal and Child Health and Precision Medicine, National and Kapodistrian University of Athens, 11527 Athens, Greece

5 College of Medicine, SUNY Upstate Medical University, Syracuse, NY 13210, USA; PerrySe@upstate.edu (S.W.P.); wongma@upstate.edu (M.-L.W.); licinioj@upstate.edu (J.L.)

6 Rayne Institute, Division of Diabetes \& Nutritional Sciences, Endocrinology and Diabetes, Faculty of Life Sciences \& Medicine, Kings College London, London SE5 9PJ, UK

7 Department of Fundamental Medicine, Chelyabinsk State University, 454001 Chelyabinsk, Russia

8 Institute of Cytology and Genetics, Siberian Branch of the Russian Academy of Science, 630090 Novosibirsk, Russia; zavjalov@bionet.nsc.ru (E.Z.); shevelev.oleg.nsk@gmail.com (O.S.); khotskin@bionet.nsc.ru (N.K.); g-kon@ngs.ru (G.K.); dotcenko@bionet.nsc.ru (A.S.K.); mmp@bionet.nsc.ru (M.M.)

9 Biophysics Laboratory, Institute of Laser Physics, Siberian Branch of the Russian Academy of Science, 630090 Novosibirsk, Russia; o.p.cherkasova@gmail.com

10 Institute of Natural Sciences and Mathematics, Ural Federal University named after the first President of Russia,620026 Ekaterinburg, Russia; a.sarapultsev@gmail.com (A.S.); Ibragimovroman98@yandex.ru (R.I.); igor81218@gmail.com (I.K.)

11 Institute of Immunology and Physiology, Ural Branch of the Russian Academy of Science, 620049 Ekaterinburg, Russia

12 Department of Child and Adolescent Psychiatry, Psychotherapy, and Psychosomatics, University of Ulm, 89075 Ulm, Germany; Joerg.Fegert@uniklinik-ulm.de

13 Traumatic Stress Studies Division, ICAHN School of Medicine at Mount Sinai, New York, NY 10029-6574, USA; rachel.yehuda@va.gov

* Correspondence: enrico.ullmann@uniklinikum-dresden.de

Received: 1 August 2020; Accepted: 2 October 2020; Published: 9 October 2020

\begin{abstract}
Variations in anxiety-related behavior are associated with individual allostatic set-points in chronically stressed rats. Actively offensive rats with the externalizing indicators of sniffling and climbing the stimulus and material tearing during 10 days of predator scent stress had reduced plasma corticosterone, increased striatal glutamate metabolites, and increased adrenal 11-dehydrocorticosterone content compared to passively defensive rats with the internalizing indicators of freezing and grooming, as well as to controls without any behavioral changes. These findings suggest that rats that display active offensive activity in response to stress develop anxiety associated with decreased allostatic set-points and increased resistance to stress.
\end{abstract}


Keywords: chronic stress; cPTSD; glutamate; striatum

\section{Introduction}

In the fight for survival, stress-related psychobiological responses are activated together with calming mechanisms [1,2]. Some authors have referred to these adaptive processes as "active (ACS) or passive (PCS) coping styles" [1], while others have described them as active offensive (AOR) or passive defensive responses (PDR). Using a description related to the allostasis paradigm, one may also refer, correspondingly, to the allostatic flight/fight/active (AFR) or allostatic freezing/passive (APR) responses [3]. The AFR involves offensive and proactive investigatory reactions toward environmental threats or stressors, a more aggressive phenotype, and a less pronounced neural and physiological response to stress than the APR. While some researchers have focused on the biological basis of these styles, including hormonal changes, neural remodeling, and gene methylation processes [4-6], others have pointed out the importance of individual differences in these responses [7-9]. The exact underlying mechanisms of these different psychobiological processes, including genetic and epigenetic changes, are unclear [10-15].

Circulating predator scent stress (PSS) glucocorticoid (GC) levels may vary with the different behavioral responses to stress. Thus, in a rat model of chronic PSS, lower plasma GCs were associated with active rather than passive responder animals [1,3]. Similarly, in other animal models of active and passive biobehavioral responses leading to calming down on stress, different allostatic set-points were observed with high and low circulating GC levels, respectively [5,16]. Furthermore, in the forced swim test, rats given subcutaneous injections of corticosterone (CORT) displayed more passive responding and depression-like behaviors than controls [17]. Taken together, these data suggest that elevated circulating CORT levels may play a causal role in promoting passive rather than active styles of responding.

The amygdala, prefrontal cortex (PFC), and ventral striatum are consistent components of the stress response, including synaptic interactions between one of the most important neurotransmitters, i.e., glutamate (Glu), and the circulating levels of CORT [18-22]. While most studies have focused on the circuits between the amygdala and PFC, they have neglected the modulatory role of striatum in the stress response, even when GCs administered directly into the dorsal striatum lead to enhanced consolidation of inhibited avoidance memory in cued water-maze training [23-26]. Finally, the striatum was linked to individual differences in the organism's response to stress, with "active coping" associated with striatal activation, as indicated by a heightened glucose uptake in this region during stress [27]. Aside from striatal changes, peculiarities in CORT reduction pathways may contribute to variations in the stress response. The first pathway of CORT reduction reflects limbic-hypothalamic-pituitary-adrenal (LHPA) axis suppression, which is in concordance with reduction of glucose uptake in the hypothalamus of AFR rats [27].

The second pathway may be linked to tissue metabolism of GCs by the $11 \beta$ hydroxysteroid

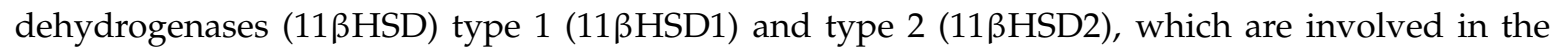
interconversion between active and inactive forms of GCs, depending on the tissue. Thus, the active form of CORT is metabolized by 11ßHSD2 to the inactive form 11-dehydrocorticosterone, while the reverse reaction from an inactive to an active form is catalyzed by the 11ßHSD type 1 enzyme [28,29]. The adrenal cortices express both $11 \beta \mathrm{HSD} 1$ and 11ßHSD2, which may be involved in not only activating, but also inactivating, calming reactions of the stress response. This suggests that the latter may also take place at the level of the end-organ of the LHPA axis, possibly via a regulated decrease of active GC secretion.

In post-traumatic stress disorder (PTSD), traumatic memories activate the striatum and inactivate the hippocampus, leading to a shift from hippocampal to striatal memory [30,31]. Indeed, functional magnetic resonance imaging (fMRI) studies in PTSD have demonstrated hippocampal-striatal 
hyperconnectivity, with lack of adaptability and decreased inter-regulation between the two regions [32]. Interestingly, reduced striatum reactivity was associated with increased vulnerability to stress in individuals exposed to early-life stress $[33,34]$. The effects of the latter on behavioral and striatal development have been well described and include both externalizing and internalizing symptoms $[35,36]$. Antidepressant-treatment-dependent increases in positive affect in depressed patients can be explained by an increase in sustained nucleus accumbens activity, while reductions of positive affect in this disorder may result in part from loss of the ability to sustain nucleus accumbens activity and connectivity with the fronto-striatal region over time [36]. Adolescents with high aggressiveness exhibited striatal activation during both reward and nonreward phases, whereas healthy controls exhibited striatal activation only during reward, shifting to anterior cingulate activation during nonreward [37].

The genotype/phenotype/endophenotype of individual differences in the psychobiological stress response is of importance and may shed light on the phenomenon of insufficient effectiveness of available therapies for depression and PTSD. According to Taghzouti et al., the antidepressant fluoxetine was effective in only a subgroup of low-stress- but not high-stress-responder rats [38]. These results were confirmed and extended with other drugs, such as desipramine [39] and citalopram or reboxetine [40], which revealed distinct effects of drugs depending on the interindividual differences of allostatic set-points of stress. In light of the above considerations, we examined whether active and passive responses to chronic predator scent test were associated with different allostatic set-points by measuring plasma CORT, striatum Glu metabolites, and adrenal gland CORT and 11-dehydrocorticosterone content. We predicted LHPA axis alterations associated with increased striatal and decreased adrenocortical activity in chronically stressed AFR rats compared to APR or control rats.

\section{Results}

\subsection{Behavior on Exposure to Stimuli (Kruskal-Wallis One-Way/Bonferroni Post Hoc Tests)}

Following exposure to the predator odor stimulus, the rat phenotypic behavioral pattern was classified into one of two groups: allostatic flight/fight response (AFR) and allostatic freezing/passive response (APR). AFR phenotypic behavioral pattern was established in $45 \%$ of the animals, and APR in the remaining $55 \%$. In general, climbing, sniffing, and tearing in AFR rats and freezing and grooming in APR rats prevailed in the direct response behavior to stress stimuli, while control rats within their cages demonstrated neutral behavioral patterns. Significant differences between AFR and APR rats were observed in the summarized number of freezing $\left(\mathrm{H}_{2,26}=15.75 ; p<0.001\right)$, grooming $\left(\mathrm{H}_{2,26}=8.85\right.$; $p=0.012)$, sniffing $\left(\mathrm{H}_{2,26}=18.88 ; p<0.001\right)$, and climbing $\left(\mathrm{H}_{2,26}=15.17 ; p<0.001\right)$ acts, as well as in the tearing the protective material of the Petri dishes $\left(\mathrm{H}_{2,26}=15.47 ; p<0.001\right)$ acts (Figure 1$)$.

After 10 days of PSS induction, hetero-chronic changes were revealed in AFR rats, which manifested a rise in climbing (with peaks on days 1-3 and 6-7; Figure 1d) and sniffing acts (with peaks on days 1-5 and 9-10; Figure 1c) and episodes of tearing/aggressive behavior (day 1-6; Figure 1e) in comparison to APR rats. AFR rats displayed decreased frequency of freezing on days 2 and 5-6 in comparison to APR rats (Figure 1a), while the latter demonstrated higher numbers of grooming behavior acts on days 7 and 9 in comparison to AFR animals (Figure 1b). In AFR rats, an upward trend in the incidence of grooming was determined (the number of grooming acts at the final stages of the experiment exceeded the ones of the initial stages). Thus, in the dynamics of 10-day PSS, only the aggressiveness was characterized by the presence of traits in AFR rats, with complete absences in APR rats. Other characteristics were revealed in both phenotypes, although with different intensities. This is why we identified the dominant behavioral patterns in the two phenotypes of rats, evaluating the differences in the summarized numbers of behavioral acts during the 10 days of PSS exposure. 


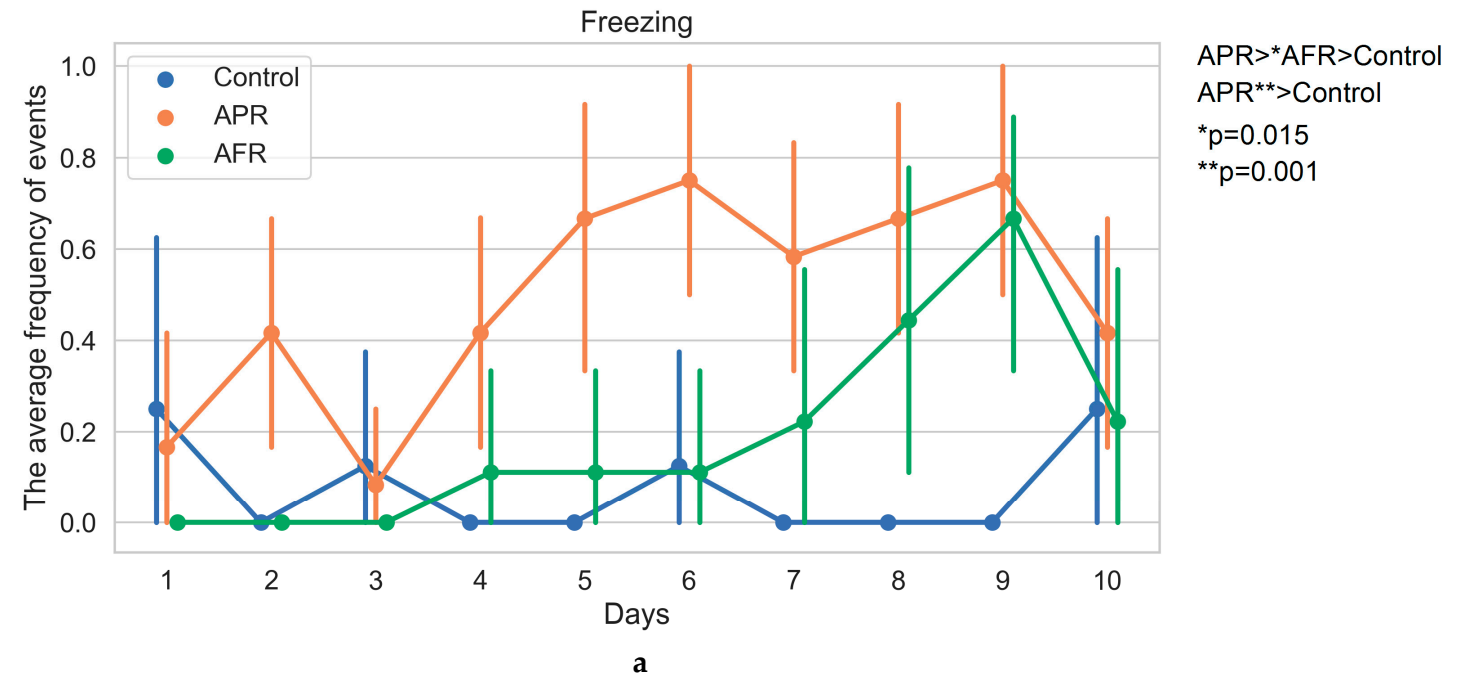

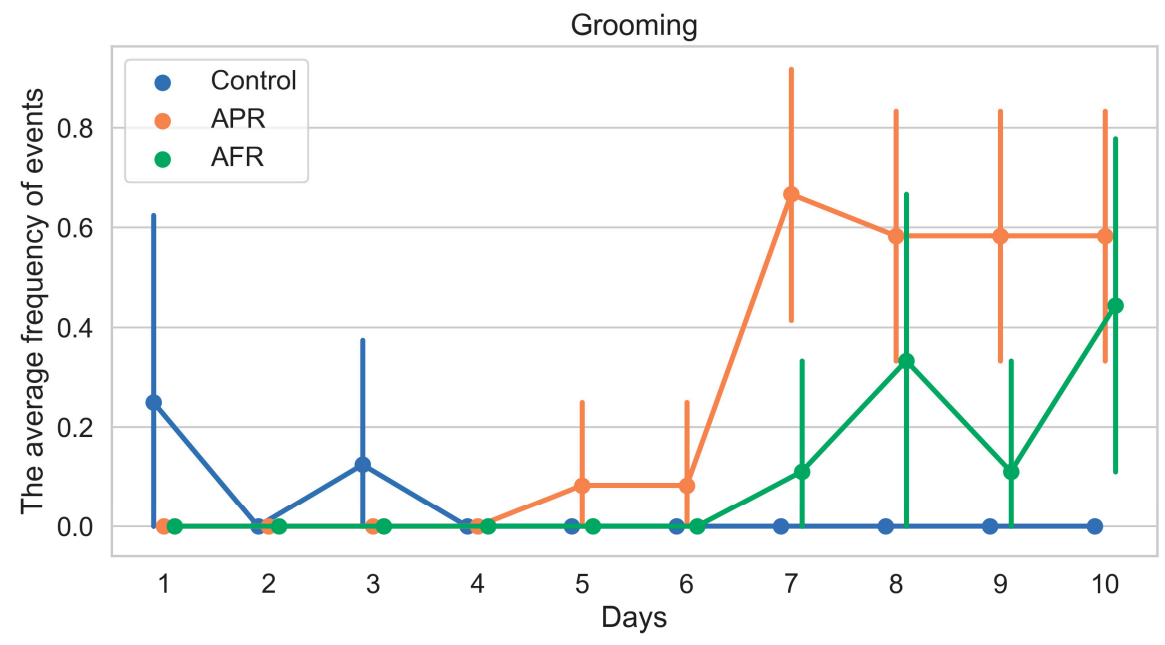

APR $>$ AFR $>$ Control $A P R^{*}>$ Control

${ }^{*} p=0.016$

b

Sniffing

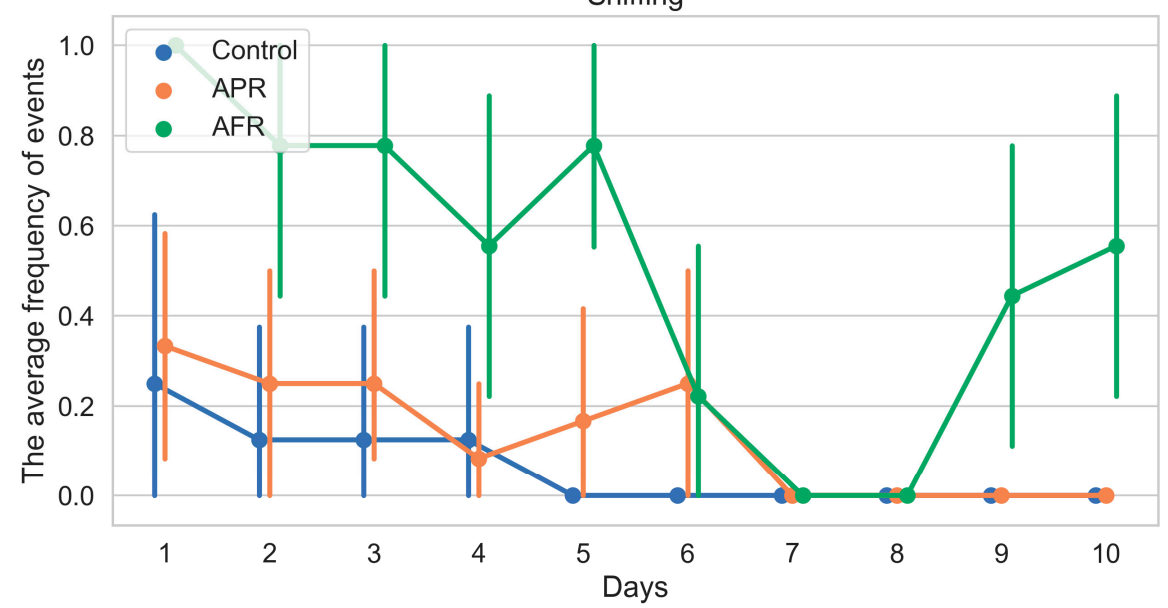

AFR $>$ *APR $>$ Control AFR ${ }^{* *}>$ Control

${ }^{*} p=0.002$

${ }^{* *} p<0.001$

Figure 1. Cont. 


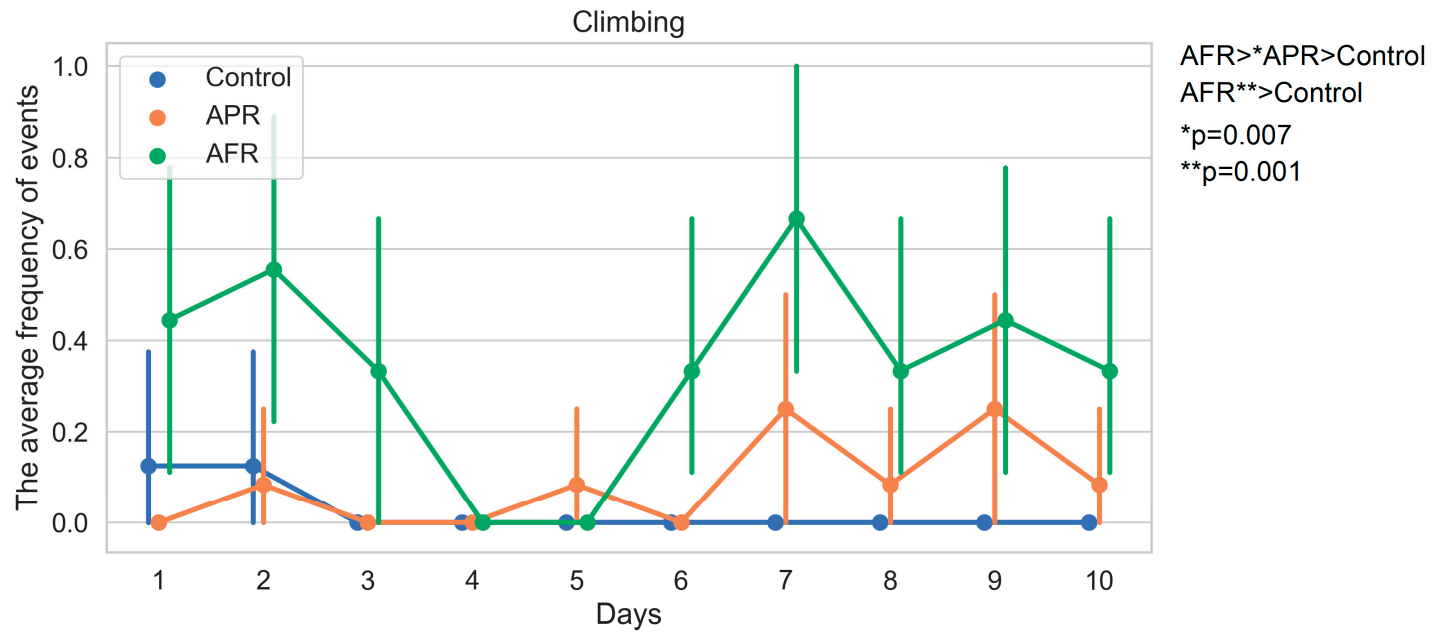

d

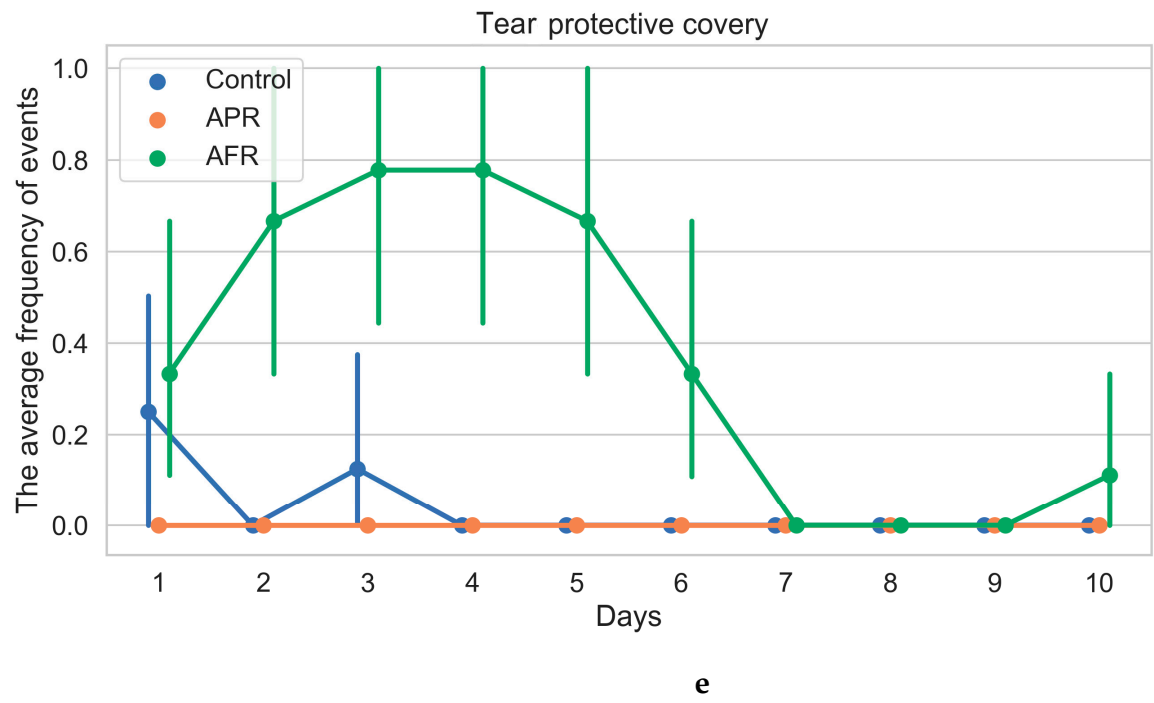

AFR $>$ Control $>$ APR AFR*APR ${ }^{*} \mathrm{p}<0.001$

Figure 1. Behavior patterns of allostatic flight/fight/active (AFR) or allostatic freezing/passive (APR) response rats. Legend: Bonferroni's calculations for $\mathrm{M} \pm \mathrm{SE}$ of (a) the frequency (per rat) of freezing behavior acts, (b) the frequency (per rat) of grooming behavior acts, (c) The frequency (per rat) of sniffing acts, (d) the frequency (per rat) of climbing acts, (e) the frequency (per rat) of attempts to tear the protective material of the Petri dishes.

\subsection{AFR and APR Rat Behavior in Elevated Plus Maze}

A significant influence of the behavioral phenotype in response to PSS on the cumulative number of entries $\left(\mathrm{F}_{2,26}=12.84 ; p<0.001\right)$, exploring $\left(\mathrm{F}_{2,26}=14.3 ; p<0.001\right)$, and time spent in the open (OA) $\left(\mathrm{F}_{2,26}=21.04 ; p<0.0001\right)$ and closed arms $(\mathrm{CA})\left(\mathrm{F}_{2,26}=23.04 ; p<0.0001\right)$ was revealed (Table 1$)$. According to the results, PSS led to a rise in OA entries ( $p=0.0025$ vs. control; $p=0.001$ vs. APR), OA exploring, and time spent in OA ( $p=0.00007$ vs. control; $p=0.0001$ vs. APR) and CA ( $p=0.0001$ vs. control; $p<0.0001$ vs. APR) in the AFR compared to APR and unstressed control rats. Overall, the different behavioral phenotypes in response to PSS exposures were characterized by the distinctions in animal anxiety levels on day 14 post PSS cessation: diminished anxiety levels were observed only in AFR rats. 
Table 1. Behavioral performance of AFR and APR rats in elevated plus maze test.

\begin{tabular}{cccc}
\hline & Control & APR & AFR \\
\hline Central square time & $0.10 \pm 0.02$ & $0.12 \pm 0.02$ & $0.19 \pm 0.01^{*, \#}$ \\
\hline$\%$ Closed arms time & $0.89 \pm 0.03$ & $0.8 \pm 0.03$ & $0.62 \pm 0.03^{*, \#}$ \\
\hline$\%$ Open arms time & $0.11 \pm 0.01$ & $0.08 \pm 0.01$ & $0.19 \pm 0.03^{*, \#}$ \\
\hline Entries into open arms & $1.32 \pm 0.24$ & $1.15 \pm 0.024$ & $4.42 \pm 0.45^{*, \#}$ \\
\hline Entries into closed arms & $4.55 \pm 0.78$ & $8.68 \pm 1.25$ & $5.43 \pm 0.35$ \\
\hline
\end{tabular}

Legend: $\overline{\text { Data presented using } \mathrm{M} \pm \mathrm{SD} ;{ }^{*} p<0.05 \text { in comparison with control }(n=8) \text {; }{ }^{*} p<0.05 \mathrm{AFR}}(n=9)$ in comparison with APR $(n=12)$.

\subsection{Biochemical Differences in Our Classified Behavioral Subtypes}

Magnetic resonance spectroscopy (MRS) analysis using a one-way ANOVA (Figure 2) revealed significant differences in summarized Glu+glutamine $(\mathrm{Gln})$ metabolites in striatum $\left(\mathrm{F}_{2,26}=6.97\right.$; $p<0.001)$, with higher Glu+Gln levels in AFR $(24.94 \pm 9.51 \%, n=9)$ than in APR rats $(17.02 \pm 5.19 \%$, $n=12 ; p<0.005)$ and when compared with control rats $(16.37 \pm 3.35 \% ; p<0.005)$, while there were no differences in Glu+Gln levels in APR rats in comparison to control animals.

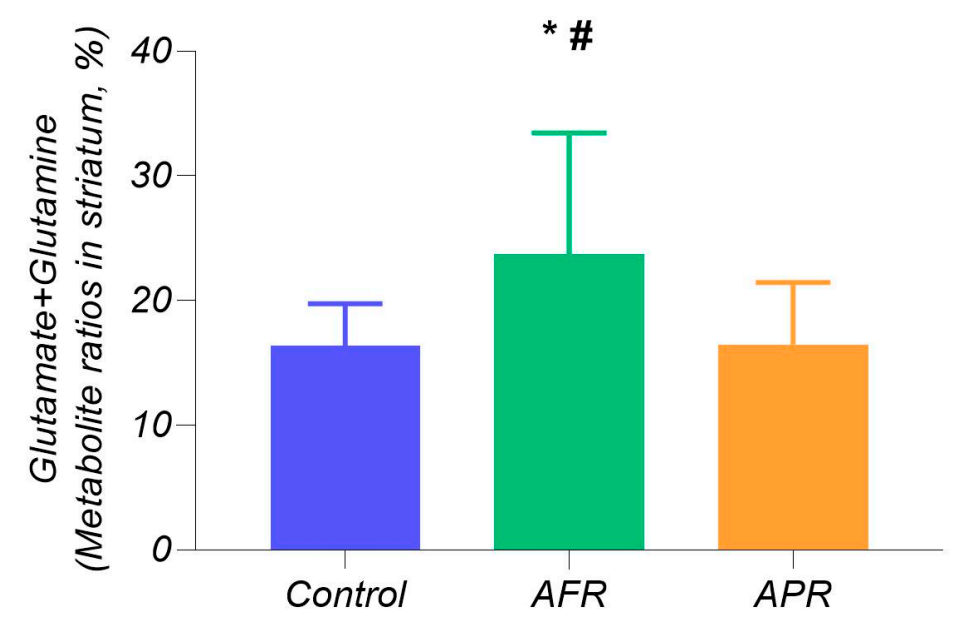

Figure 2. Long-term consequences of predator scent stress (PSS) in rat striatum. Legend: Total metabolite $(\%)$ glutamate+glutamine concentrations. ${ }^{*} p<0.05$ in comparison with APR $(n=12)$; $\# p<0.05 \operatorname{AFR}(n=9)$ in comparison with control.

Even 18 days after PSS induction (Figure 3a), differences in plasma CORT levels were significant $\left(\mathrm{F}_{2,26}=6.71 ; p<0.01\right)$ : hormone levels in AFR rats $(16.61 \pm 6.59 \mathrm{ng} / \mathrm{mL}, n=9)$ were lower than in APR $(58.63 \pm 23.54 \mathrm{ng} / \mathrm{mL}, n=12 ; p=0.007)$ and control animals $(41.18 \pm 17.23 \mathrm{ng} / \mathrm{mL}, n=8 ; p=0.049)$, while no differences were revealed between APR and control animals.

The adrenal concentrations of CORT and 11-dehydrocorticosterone (as an inactivated derivative of CORT) were examined to evaluate the balance between GC production and inactivation in AFR and APR rats 18 days post PSS cessation. The analysis, conducted via a one-way ANOVA, did not reveal any significant effects of the behavioral response to PSS on CORT $\left(\mathrm{F}_{2,26}=0.74 ; p=0.52\right)$; however, 11-dehydrocorticosterone levels (Figure $3 b)$ were different $\left(\mathrm{F}_{2,26}=3.7 ; p=0.041\right)$ between either group of stressed rats (AFR and APR) and controls: AFR rats $(0.85 \pm 0.13 \mathrm{ng} / \mathrm{mg}, n=9)$ were characterized by higher 11-dehydrocorticosterone levels than APR $(0.66 \pm 0.049 \mathrm{ng} / \mathrm{mg}, n=12 ; p=0.0006)$ and control $(0.69 \pm 0.11 \mathrm{ng} / \mathrm{mg}, n=8 ; p=0.019)$ rats, while the 11-dehydrocorticosterone level reduction in APR was similar to that of the control $(p=0.25)$ rats. Moreover, the 11-dehydrocorticosterone/CORT ratio was different $\left(\mathrm{F}_{2,26}=3.7 ; p=0.041\right)$ between both groups of stressed rats (AFR and APR). AFR rats $(35.04 \pm 11.25 n=9)$ were characterized by lower CORT/11-dehydrocorticosterone ratio than 
APR $(55.16 \pm 16.12 n=12 ; p=0.0006)$ and control rats $(52.33 \pm 18.25 ; n=8 ; p=0.033)$, while the 11-dehydrocorticosterone/CORT ratio in APR rats was similar to that of the control $(p=0.25)$.

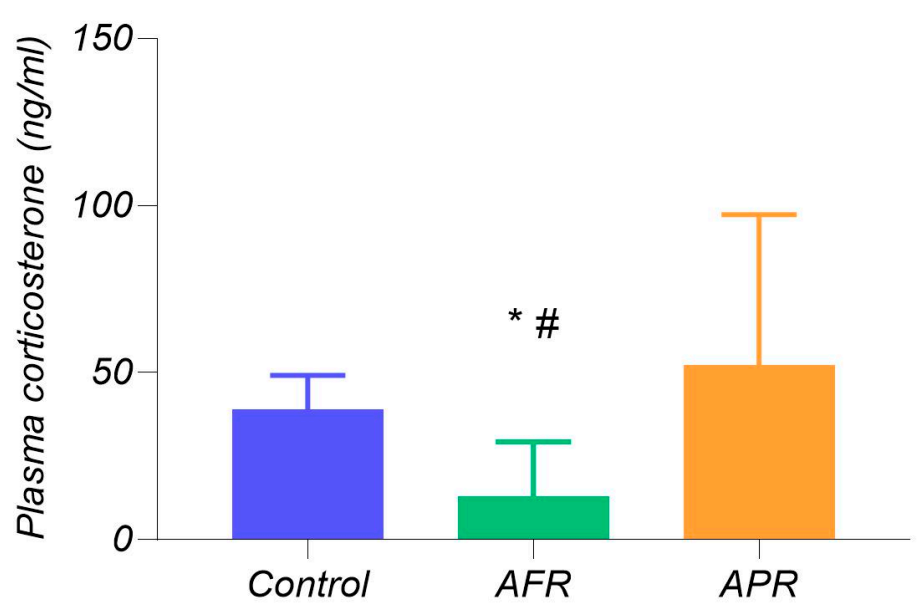

a

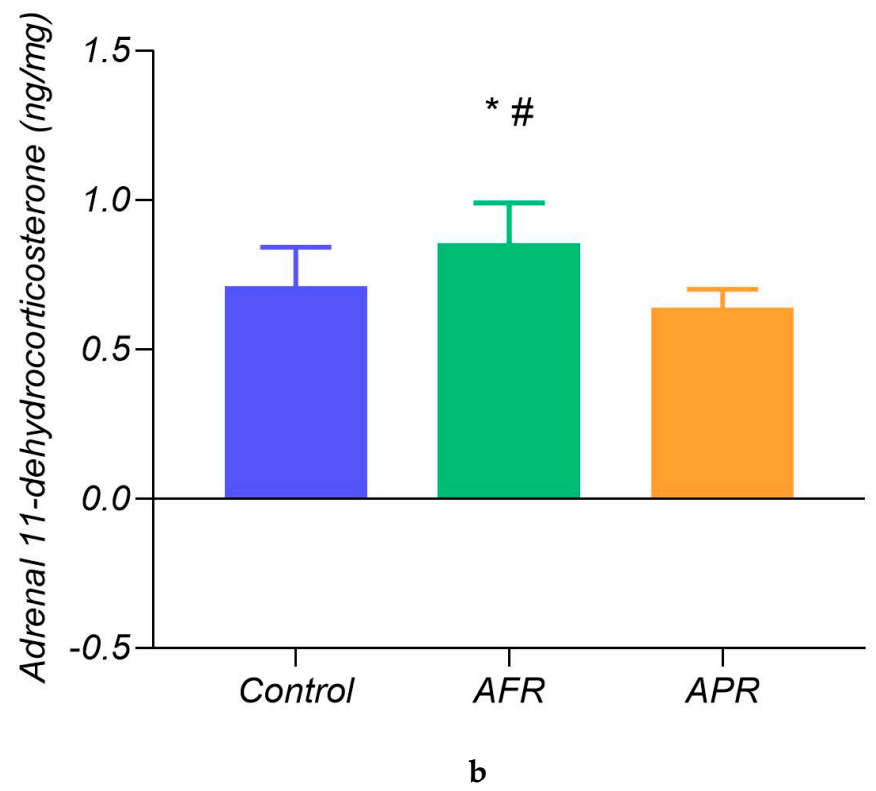

Figure 3. Comparison of peripheral corticosteroids 18 days after PSS. Legend: (a) Plasma CORT levels $(\mathrm{ng} / \mathrm{mL})$ and $(\mathbf{b})$ adrenal 11-dehydrocorticosterone levels (ng/mg of tissue). \# $p<0.05$ AFR $(n=9)$ in comparison to APR $(n=12)$.); ${ }^{*} p<0.05$ in comparison to control $(n=8)$.

\section{Discussion}

The results obtained in this study allowed us to propose a link between "coping style" and related behavioral patterns in PSS exposure. Thus, animals with an offensive response to chronic predator stress (AFR) not only exhibited the lowest anxiety levels in response to the stressor [3], but also had higher striatal glutamate metabolite concentrations, as well as lower basal plasma CORT, and higher 11-dehydrocorticosterone in the adrenal glands than APR rats and controls. This observation is consistent with our previous data, where the anxiety extinction after stress exposure, accompanied by higher lactate (lac) and lower Glu levels in the amygdala, another main driver of the anxiety response [18-22,41] as observed in AFR animals [3]. Taken together, our results suggest a novel mechanism of transient hypocorticosteronemia in tissues, with corticosterone being suppressed in 
situ in the adrenal glands. It is important that this is reversible and that the pool of the synthesized corticosterone could be restored rapidly (Figure 4).

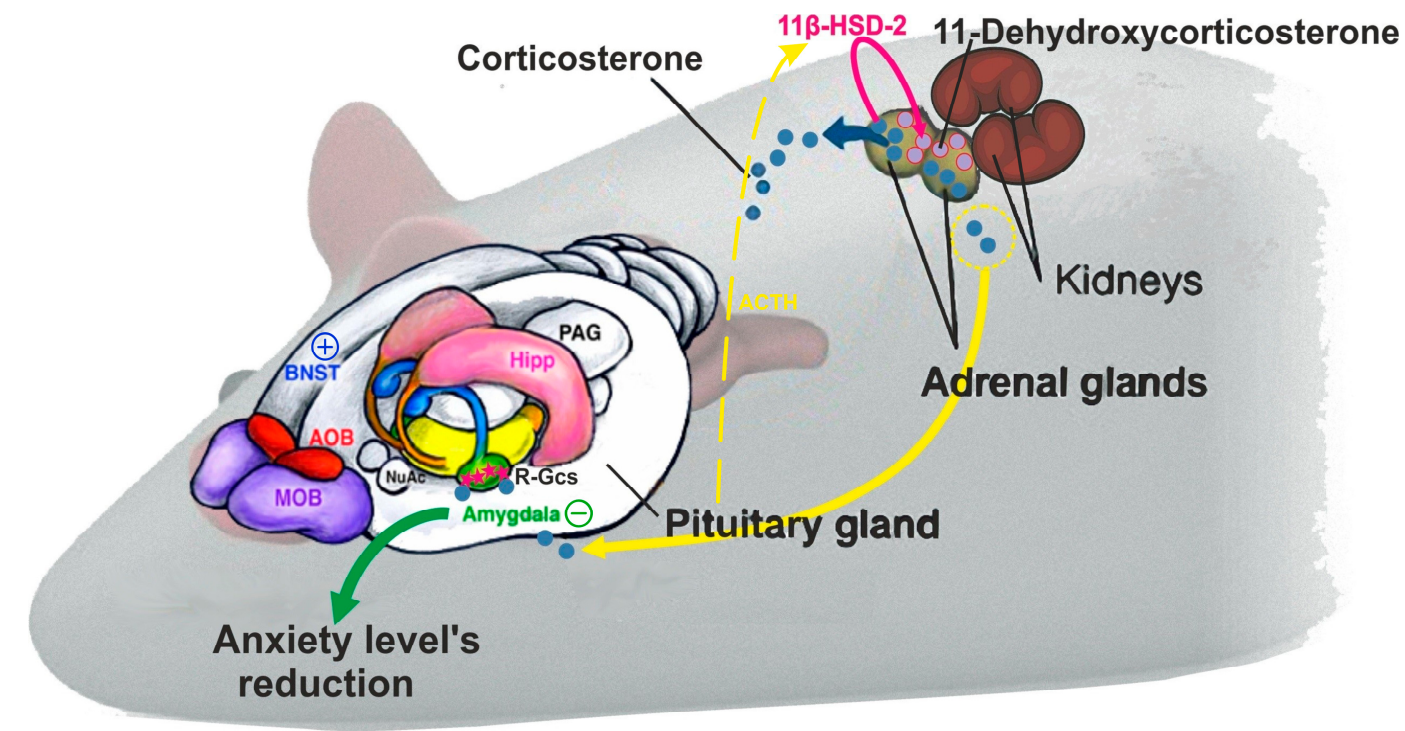

Figure 4. Parallel behavioral and brain biochemical changes in AFR rats. Legend: Hypocorticosteronemia in AFR rats develops as a result of corticosterone inactivation by $11 \beta$ HSD2 in the adrenal glands. Low corticosterone levels contribute to inhibition of amygdala activity, which manifests as a decrease in glutamate (Glu)/glutamine (Gln) ratio and an increase in lactate (Lac) in this brain structure [3]. A parallel increase in the excitatory neurotransmitter Glu+Gln in the striatum possibly indicates activation of this brain structure. Inhibition of the amygdala and activation of the striatum possibly lead to a decrease in the anxiety of AFR rats. The observed decrease in corticosterone is most likely transient and rapidly restorable. The red stars indicated "R-Gcs" (Gluccocorticoid receptors of the amygdala).

Granted that active coping style pertains to the flight/fight response, while passive coping style corresponds to freezing/passive response $[1,5,16]$, it makes sense that high CORT levels in APR animals are associated with a passive coping strategy. This is in agreement with data in primates and rodents, in which high basal and stress-induced cortisol levels have been associated with increased freezing [42,43]. Similarly, preventing CORT release in newborn rats by removing the adrenals leads to impaired freezing, which can be restored by glucocorticoid administration [44].

According to Schwabe et al., psychobiological mechanisms of stress-resilience are associated with an active response to stress stimuli and a bias toward the use of stimulus-response (S-R) learning; the striatum is a key player in the implementation of S-R learning, and this was indirectly confirmed by data from striatal NMR spectroscopy [2]. Our method, as applied here, has revealed an increase in striatal Glu+Gln in AFR compared to APR rats. The elevation of the major excitatory neurotransmitter Glu in AFR animals reflects activation of the striatum, which corresponds to S-R learning in rats with an active coping style $[2,25,27]$. Interestingly, the striatum showed no changes in Glu+Gln during early stress, but rather, a significant increase was observed in the late period, relative to changes in neutral runs [32]. An opposite dynamic response to stress was seen in other regions, including the hippocampus, with increases in neural activity in the early period, followed by reduced activity later; these changes are suggestive of an adaptive or habituation network part of the adaptive response to stress [32]. The observed increase in striatal activity may buffer against the effect of negative experiences on the development of post-traumatic manifestations [45]. This would explain the low anxiety levels we observed in AFR rats.

Elevated levels of the inactive GC 11-dehydrocorticosterone were detected in the adrenal glands of AFR rats. Taking into account that the rat adrenal glands have much higher 11ßHSD2 than 11ßHSD1 
activity [46], we could not rule out a decrease of CORT release by $11 \beta H S D 2$ activation preventing its


mice, which display compensatory adrenal hyperplasia and increased basal levels of corticosterone, despite the presumed absence of hepatic 11-dehydrocorticosterone to corticosterone conversion [47]. In addition, 11ßHSD2 provides protection of the target tissues and modulates circulating levels of CORT, as shown in birds [48]. Moreover, peripheral antagonism of the 11ßHSD system has a greater impact on circulating glucocorticoid levels than central control during the stress response, and this system, in turn, could be influenced by ACTH, which caused a 5-10 fold increase in 11BHSD2 mRNA in primary cultures of rat adrenocortical cells [49]. The unique advantage of such local regulation is that the adrenal cortex could rapidly and reversibly modify the secreted ratio of the inactive to the active form of CORT. A rapid transition of this ratio might serve as an advantage of AFR over APR animals by preventing negative effects associated with a long-term decrease in GC levels. As the adrenal cortices express both $11 \beta \mathrm{HSD} 1$ and $11 \beta \mathrm{HSD} 2$, we postulate that both activating and inactivating reactions may take place, representing a previously unsuspected rapid regulatory mechanism of the stress response.

\section{Materials and Methods}

Experiments were performed on 29 genetically similar white male Sprague Dawley rats, each weighing 240-260 g (age of 8-9 weeks), obtained from the specific-pathogen-free (SPF) vivarium of the Institute of Cytology and Genetics SB RAS (Novosibirsk, Russian Federation). Rats were housed in sibling pairs in standard ventilated cages (IVC BlueLine, Tecniplast, Italy). Water and granulated forage (Sniff, Soest, Germany) were given ad libitum. Animals were kept in a $14 \mathrm{~h}$ light (2 a.m. to 4 p.m.) and $10 \mathrm{~h}$ dark (4 p.m. to 2 a.m.) cycle, temperature $\left(22-24{ }^{\circ} \mathrm{C}\right)$, and relative humidity $(40-50 \%)$ controlled environment. The behavioral task was always initiated at the start of the dark cycle, when rodents are most active.

All animal experiments conformed to the requirements of the Council for International Organizations of Medical Sciences (CIOMS) and the International Council for Laboratory Animal Science (ICLAS), as described in "International Guiding Principles for Biomedical Research Involving Animals" (2012). The handling of all animals was identical. The study protocol was approved by the Committee for Bioethics and Humane Treatment of Laboratory Animals at South Ural State University, Russia (Project 0425-2018-0011 from 17 May 2018, protocol number 27/521).

\subsection{Experimental Procedure}

Following exposure to the predator odor stimulus, the rat phenotypic behavioral pattern was classified into one of two groups: allostatically active flight/fight response (AFR), i.e., rats exhibiting a "stimulus-response" behavior pattern, and allostatically freezing/passive response (APR) groups [3,50,51].

For the PSS protocol, rats were exposed to cat urine scent in a Petri dish with litter for $10 \mathrm{~min}$ daily for 10 days ( 21 rats were submitted to stress exposure; 8 control rats were exposed to a neutral scent). Repeated exposure to the PSS may be a more accurate model of human PTSD than the single acute exposure approach, granted that it minimizes the effect of confounding factors, such as the concentration of pheromones in each individual urine scent exposure [3,52]. All procedures were performed between 1:00 and 2:00 p.m. During the scent exposure protocol, stress-related behavior was captured daily via web-camera. Behavioral evaluation was conducted via 3D animal tracking system "EthoStudio" [53]. The evaluator of the behavior had not previously worked with any rats in our groups. Recorded variables included the time spent in open and closed arms of the maze and the number of entries into the open and closed arms.

The timeline for modeling PSS, evaluating stress-related behavior and anxiety, and measuring of metabolites (CORT, Glu+Gln and 11-dehydrocorticosterone) in plasma, brain, and adrenal glands, respectively, was as follows:

1. Days 1-10: PSS; 
2. Days 11-22: rest;

3. Day 23: elevated plus maze test;

4. Day 27: striatum metabolite measurement by MRS;

5. Day 28: euthanasia, harvesting of blood and organs.

\subsection{Behavioral Activity}

Video recordings of PSS sessions were made in the home cages. The presence or absence of behavioral responses was recorded daily. The frequencies of freezing, grooming, sniffing of stimuli, climbing on stimuli, and tearing of protective cover of stimuli were used for classification of rats as AFR and APR. The presence of the response in one session was marked with " 1 ", while the lack of a response was marked as " 0 ". Apart from registration of the daily changes of the observed behavioral responses, we also summarized the frequencies of these behavioral responses over 10 days. The predator stress outcome was evaluated using the elevated plus maze test, using the standard elevated plus maze (EPM) test apparatus TS0502-R3 (OpenScience, Russia) [54,55]. Variables recorded included time spent in open and closed arms of the maze and the number of entries into the open and closed arms. While Table 1 demonstrates the measurements of the maze, Figure 1 reflects the dynamics of rat behavior in home cages during the 10 days of PSS.

\subsection{Magnetic Resonance Spectroscopy (MRS)}

Rat striatum neurometabolites (Figure 2) were measured on a horizontal tomograph with a magnetic field of 11.7 tesla (Bruker, Biospec 117/16 USR, Germany). The rats were anesthetized with gas (isoflurane; Baxter Healthcare Corp., Deerfield, IL, USA) using a Univentor 400 Anesthesia Unit (Univentor, Zejtun, Malta). The tomographic table contained a water circuit that maintained a surface temperature of $30^{\circ} \mathrm{C}$ to preserve animal body temperature during the test. A pneumatic respiration sensor (SA Instruments, Stony Brook, NY), placed under the lower body, controlled the depth of anesthesia. Proton spectra of the rat striatum were recorded with transmitter volume (T11232V3) and rat brain receiver surface (T11425V3) using $1 \mathrm{~Hz}$ radiofrequency coils (Bruker, Ettlingen, Germany). High-resolution T2-weighted images of the rat brain in three (axial, sagittal, and coronal) dimensions (section thickness, $0.5 \mathrm{~mm}$; field of view, $2.5 \times 2.5 \mathrm{~cm}$ for axial and $3.0 \times 3.0 \mathrm{~cm}$ for sagittal and coronal sections; matrix of $256 \times 256$ dots) were recorded by rapid acquisition with relaxation enhancement (TurboRARE), with the pulse sequence parameters TE $=11 \mathrm{~ms}$ and TR $=2.5 \mathrm{~s}$ for correct positioning of the spectroscopic voxels. Voxel dimension was $3.0 \times 3.0 \times 3.0 \mathrm{~mm}$ for the striatum. Voxel was manually placed according to a structural T2-weighted MRI image (Figure 5). All proton spectra were recorded by spatially localized single-voxel stimulated echo acquisition mode (STEAM) spectroscopy, with the following pulse sequence parameters: $\mathrm{TE}=3 \mathrm{~ms}, \mathrm{TR}=5 \mathrm{~s}$, and 120 accumulations. Uniformity of the magnetic field was tuned within the selected voxel using FastMap [56] before each spectroscopic recording. The water signal was inhibited with a variable pulse power and optimized relaxation delays (VAPOR) sequence [57]. 

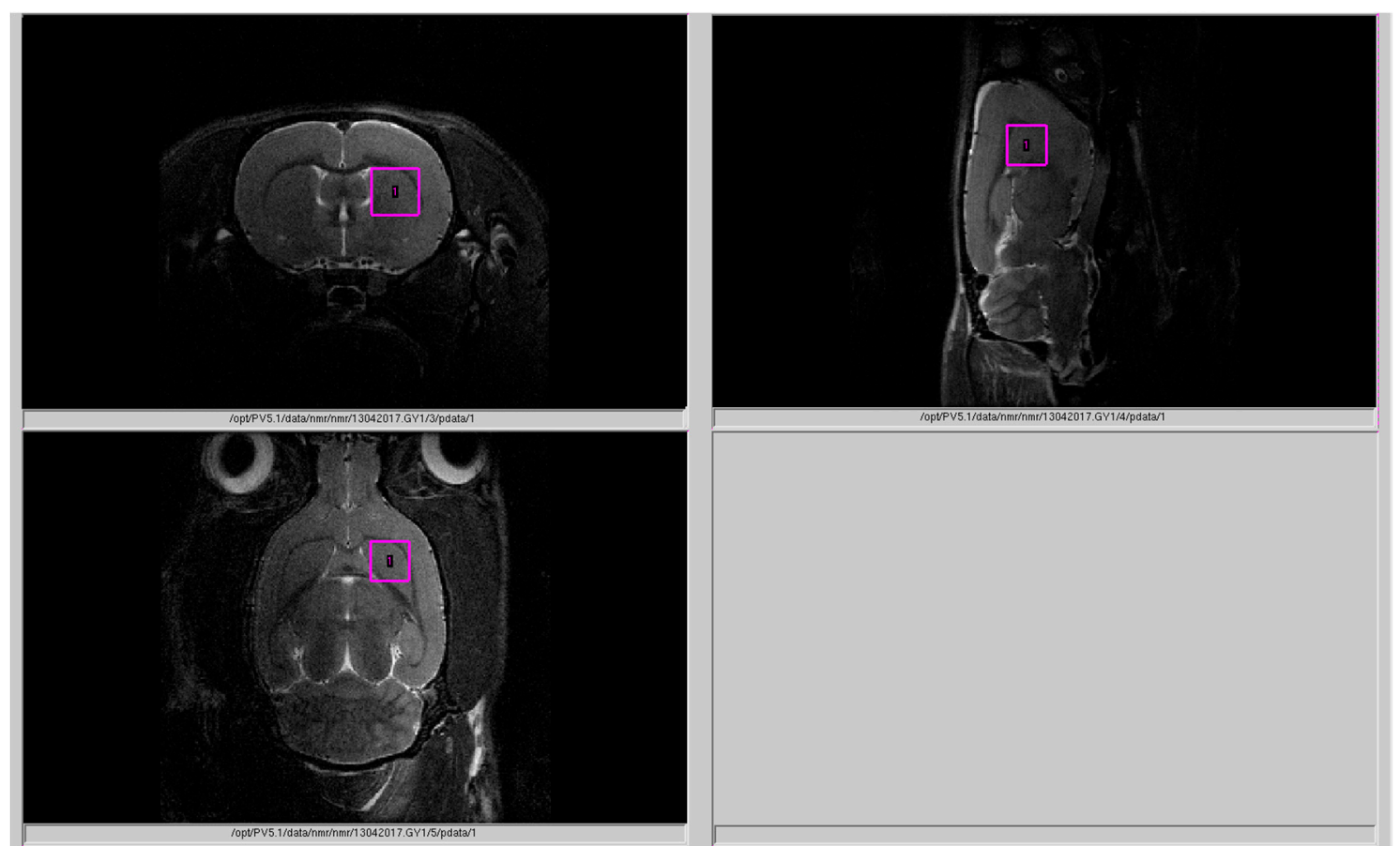

Figure 5. MRS measurements in the striatal region. The labeled pink area indicated the: "Voxel position during $1 \mathrm{H}$ MRS of the striatum".

\subsection{Processing of ${ }^{1} \mathrm{H}$ Spectra}

The experimental ${ }^{1} \mathrm{H}$ magnetic resonance spectra were processed, and the quantitative composition of metabolites was determined with a custom-made program similar to that of the LC Model software package $[58,59]$. The baseline correction was conducted automatically by the program to determine the spectral baseline for fitting of the spectrum obtained by ${ }^{1} \mathrm{H}$ MRS. The process of fitting was presented on the real-time plot, and the fitted data were stored in numerical form.

\subsection{Hormonal Measurements}

Between 11:00 a.m. and 1:00 p.m. on experimental day 28, rats were sacrificed by decapitation, and blood samples were collected in tubes with heparin. Blood samples (Figure 3) were then centrifuged at $3000 \mathrm{rpm}$ at $4{ }^{\circ} \mathrm{C}$ for $15 \mathrm{~min}$. Plasma samples were aliquoted and stored in a $-80^{\circ} \mathrm{C}$ freezer until use. After thawing, plasma CORT concentrations were measured by ELISA (Cusabio ELISA Kit, Texas, USA) as per manufacturer's instructions. The assay sensitivity was $0.25 \mathrm{ng} / \mathrm{mL}$, and the intra- and interassay coefficients of variation were both $<5 \%$.

High-performance liquid chromatography (HPLC) using the micro-column liquid chromatograph Milikhrom-1 (NPO "Nauchpribor", Orel, Russia) for the evaluation of corticosteroids (CORT and 11-dehydrocorticosterone) in rat adrenal glands (Figure 4) was carried out on experimental day 28. The entire procedure of adrenal CORT extraction, measurements, and validation was previously described in detail $[60,61]$. The adrenal glands were weighed, transferred into a glass homogenizer, placed into an ice bath, and thoroughly homogenized in $1 \mathrm{~mL}$ of cold acetone. The homogenates were transferred to plastic tubes, and the samples were centrifuged at $2000 \mathrm{~g}$ at $4{ }^{\circ} \mathrm{C}$ for $15 \mathrm{~min}$. The supernatants were then poured into a plastic tube and evaporated in a nitrogen flow at $40{ }^{\circ} \mathrm{C}$. The residues were dissolved in $24 \mu \mathrm{L}$ of a $65 \%$ solution of $\mathrm{CH} 3 \mathrm{OH}$ in water. The injection volumes were $8 \mu \mathrm{L}$. Determinations of corticosteroid hormones were carried out using micro-column high-performance liquid chromatography (HPLC) [62]. Chromatographic conditions were as follows: steel column $2 \times 62 \mathrm{~mm}$ in size, packed with Silasorb C18 SPH $8(5 \mu \mathrm{m})$ as sorbent, gradient elution with acetonitrile in water from 30 to $55 \%(v / v)$, eluting rate of $100 \mu \mathrm{L} / \mathrm{min}$, and UV detection at 240 and 
$260 \mathrm{~nm}$. The wavelengths were chosen because of the absorption spectrum of steroid hormones: $240 \mathrm{~nm}$ corresponds to the maximal absorption of the majority of corticosteroid hormones, while $260 \mathrm{~nm}$ corresponds to half of the maximal absorption. Chromatographic information was processed with the help of CHROM software (EcoNova, Institute of Chromatography, Novosibirsk, Russia).

Hormone identification was performed by comparing retention times and spectral ratios of endogenous corticosteroids and synthetic standards. The amounts of the corticosteroids were determined in nanograms per $\mathrm{mg}$ of tissue $(\mathrm{ng} / \mathrm{mg})$ using calibration curves plotted individually for each hormone under investigation. Chromatographic separation of a mixture of standards (a) $(\mathrm{C}=10 \mathrm{ng} / \mu \mathrm{L}, 5 \mu \mathrm{L}$ was taken for the analysis) and adrenal extracts (b) is shown in Figure 6.

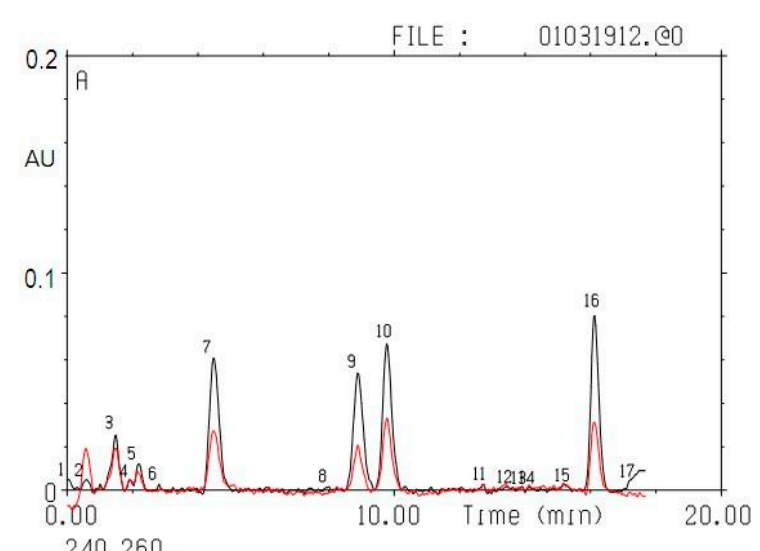

$\underline{240} \underline{260}$

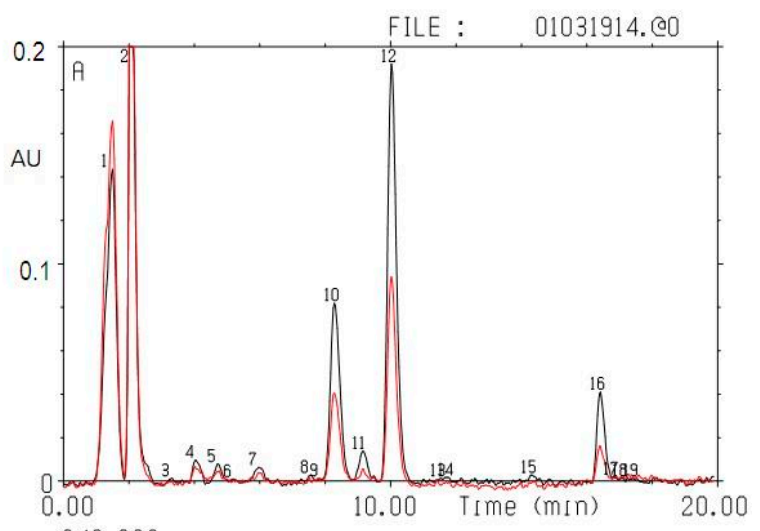

$\underline{240} 260$

(a)

(b)

Figure 6. Chromatographic separation of a mixture of standards (a): 7-aldosterone, 9 -11-dehydrocorticosterone, 10-corticosterone, and 16-11-desoxycorticosterone; and adrenal extracts (b): 5-aldosterone, 11 -11-dehydrocorticosterone, 12-corticosterone, and 16-11-desoxycorticosterone. The black line corresponds to absorption at $240 \mathrm{~nm}$, the red line to absorption at $260 \mathrm{~nm}$. The y-axis is absorption (A) in absorption units (AU); the $\mathrm{x}$-axis is time in min.

\subsection{Data Analyses}

Data were analyzed with SPSS 24, STATISTICA 10.0 and MS Excel software. Quantitative data were presented as mean \pm SEM. After having shown normal distribution by the Shapiro-Wilk test, a one-way ANOVA with Fisher's LSD post hoc tests and the Kruskal-Wallis with Bonferroni corrected post hoc tests were used to compare all outcome measures between two groups (e.g., control vs. AFR, control vs. APR, AFR vs. APR). $p<0.05$ was considered significant.

\section{Conclusions}

The LHPA axis coordinates behavioral and physical responses to chronic stressors, with the striatum acting as a player in the implementation of the active offensive behavior. GCs modulate the activity of the striatum. In our study, we observed activation of the striatum, an important component of an active behavioral strategy that was accompanied by decreased GC levels. This decrease was seen in a relatively distant period from the timing of the stressor. Other investigators described activation of the striatum at earlier time intervals relative to the timing of the stressor, which was probably associated with elevated GC levels. Lower CORT levels in blood might be related to decreased activity of the HPA axis and/or increased adrenal conversion to 11-dehydrocorticosterone. In the latter case, we demonstrated a transient hypocorticosteronemia, which might quickly level out or turn into hypercorticosteronemia. Our data might have some clinical implications suggesting that individuals with more externalizing behaviors (more active offensive response to chronic stress), have less anxiety and lower basal CORT levels compared to individuals with more internalizing 
behaviors (freezing/passive response to chronic stress), indicating a lower allostatic set-point with higher resistance to stress in externalizing individuals.

\section{Limitations of the Study}

The main limitation of this study was that we did not investigate the activity and expression of $11 \beta$ HSD1 and -2 in peripheral tissues beyond the adrenal glands. Further studies will examine this issue to establish adrenal and non-adrenal factors that might regulate CORT metabolism. We should also emphasize that CORT levels and patterns discussed here might not correspond to those that could be observed after the initial exposure. Thus, according to Dopfel et al., in low-freezing (i.e., active) animals, the CORT response immediately after stress exposure was heightened and prolonged and had a delayed return to baseline, a pattern of CORT response that has been suggested as a marker of maladaptation to stress in individuals who develop PTSD [9]. With time, this pattern of CORT response may change through several processes, including changes in adrenal enzymatic activity, as shown in this study.

Author Contributions: E.U., V.T., and R.Y. organized the whole study, wrote the main manuscript (with data analyses), and prepared the figures and tables. E.Z., O.S., N.K., G.K., A.S.K., M.M., and O.C. collected the samples and analyzed the biomarkers in Novosibirsk. M.S.L., M.K., M.V. and O.T. designed the work plan together with the corresponding author (E.U.) and the team leaders (R.Y. and V.T.) and formulated the scientific questions. A.S., R.I., and I.K. prepared the statistical analyses and the figures together with the corresponding author (E.U.) and the team leaders (R.Y. and V.T.). G.C., S.R.B., S.W.P., J.L., M.-L.W., and J.M.F. went over the data analyses and edited the main manuscript. All authors reviewed the manuscript. There was no other personal, financial, or material support. All authors declare that they have no financial interests. All authors have read and agreed to the published version of the manuscript.

Funding: The Russian Science Foundation (grant \#17-15-013418) supported this study. This was supported in part by the contracts of the Ministry of Education and Science of the Russian Federation with South Ural State University (17.7255.2017/8.9) and Institute of Immunology and Physiology (AAAA-A18-118020690020-1). The work was furthermore supported by institutional funds from the State University of New York (SUNY) Upstate Medical University. This work is part of the TransCampus project between TU Dresden and King's College London and was partially supported by the U.S. Department of Veterans Affairs (5101CX001219) and the U.S. Department of Defense (W81XWH-16-1-0773).

Conflicts of Interest: The authors declare no conflict of interest.

\section{References}

1. Bowen, M.T.; Dass, S.A.H.; Booth, J.; Suraev, A.; Vyas, A.; McGregor, I.S. Active coping toward predatory stress is associated with lower corticosterone and progesterone plasma levels and decreased methylation in the medial amygdala vasopressin system. Horm. Behav. 2014. [CrossRef] [PubMed]

2. Schwabe, L.; Dalm, S.; Schächinger, H.; Oitzl, M.S. Chronic stress modulates the use of spatial and stimulus-response learning strategies in mice and man. Neurobiol. Learn. Mem. 2008, 90, 495-503. [CrossRef] [PubMed]

3. Ullmann, E.; Perry, S.W.; Licinio, J.; Wong, M.L.; Dremencov, E.; Zavjalov, E.L.; Shevelev, O.B.; Khotskin, N.V.; Koncevaya, G.V.; Khotshkina, A.S.; et al. From allostatic load to allostatic state-An endogenous sympathetic strategy to deal with chronic anxiety and stress? Front. Behav. Neurosci. 2019. [CrossRef] [PubMed]

4. Holmes, S.E.; Girgenti, M.J.; Davis, M.T.; Pietrzak, R.H.; DellaGioia, N.; Nabulsi, N.; Matuskey, D.; Southwick, S.; Duman, R.S.; Carson, R.E.; et al. Altered metabotropic glutamate receptor 5 markers in PTSD: In vivo and postmortem evidence. Proc. Natl. Acad. Sci. USA 2017, 114, 8390-8395. [CrossRef]

5. Korte, S.M.; Meijer, O.C.; de Kloet, E.R.; Buwalda, B.; Keijser, J.; Sluyter, F.; van Oortmerssen, G.; Bohus, B. Enhanced 5-HT1A receptor expression in forebrain regions of aggressive house mice. Brain Res. 1996, 736, 338-343. [CrossRef]

6. McEwen, B.S. Neurobiological and Systemic Effects of Chronic Stress. Chronic Stress 2017, 1, 2470547017692328. [CrossRef] [PubMed]

7. Goldstein, M.J. Individual differences in response to stress. Am. J. Community Psychol. 1973, 1, 113-137. [CrossRef] 
8. Ebner, K.; Singewald, N. Individual differences in stress susceptibility and stress inhibitory mechanisms. Curr. Opin. Behav. Sci. 2017, 14, 54-64. [CrossRef]

9. Dopfel, D.; Perez, P.D.; Verbitsky, A.; Bravo-Rivera, H.; Ma, Y.; Quirk, G.J.; Zhang, N. Individual variability in behavior and functional networks predicts vulnerability using an animal model of PTSD. Nat. Commun. 2019, 10, 2372. [CrossRef]

10. Yehuda, R.; Flory, J.D.; Pratchett, L.C.; Buxbaum, J.; Ising, M.; Holsboer, F. Putative biological mechanisms for the association between early life adversity and the subsequent development of PTSD. Psychopharmacology (Berl) 2010, 212, 405-417. [CrossRef]

11. Yehuda, R.; LeDoux, J. Response variation following trauma: A translational neuroscience approach to understanding PTSD. Neuron 2007, 56, 19-32. [CrossRef] [PubMed]

12. Koolhaas, J.M. Coping style and immunity in animals: Making sense of individual variation. Brain Behav. Immun. 2008, 22, 662-667. [CrossRef] [PubMed]

13. Feder, A.; Nestler, E.J.; Charney, D.S. Psychobiology and molecular genetics of resilience. Nat. Rev. Neurosci. 2009, 10, 446-457. [CrossRef] [PubMed]

14. Lapp, H.E.; Ahmed, S.; Moore, C.L.; Hunter, R.G. Toxic stress history and hypothalamic-pituitary-adrenal axis function in a social stress task: Genetic and epigenetic factors. Neurotoxicol. Teratol. 2019, 71, 41-49. [CrossRef]

15. Zhou, Z.; Zhu, G.; Hariri, A.R.; Enoch, M.-A.; Scott, D.; Sinha, R.; Virkkunen, M.; Mash, D.C.; Lipsky, R.H.; $\mathrm{Hu}, \mathrm{X}$.-Z; ; et al. Genetic variation in human NPY expression affects stress response and emotion. Nature 2008, 452, 997-1001. [CrossRef]

16. Korte, S.M.; Bouws, G.A.H.; Koolhaas, J.M.; Bohus, B. Neuroendocrine and behavioral responses during conditioned active and passive behavior in the defensive burying/probe avoidance paradigm: Effects of ipsapirone. Physiol. Behav. 1992, 52, 355-361. [CrossRef]

17. Gregus, A.; Wintink, A.J.; Davis, A.C.; Kalynchuk, L.E. Effect of repeated corticosterone injections and restraint stress on anxiety and depression-like behavior in male rats. Behav. Brain Res. 2005, 156, 105-114. [CrossRef]

18. Popoli, M.; Yan, Z.; McEwen, B.S.; Sanacora, G. The stressed synapse: The impact of stress and glucocorticoids on glutamate transmission. Nat. Rev. Neurosci. 2011, 13, 22-37. [CrossRef]

19. Dunn, A.J.; Swiergiel, A.H. The role of corticotropin-releasing factor and noradrenaline in stress-related responses, and the inter-relationships between the two systems. Eur. J. Pharmacol. 2008, 583, 186-193. [CrossRef]

20. Cuadra, G.; Zurita, A.; Lacerra, C.; Molina, V. Chronic stress sensitizes frontal cortex dopamine release in response to a subsequent novel stressor: Reversal by naloxone. Brain Res. Bull. 1999, 48, 303-308. [CrossRef]

21. Gardner, K.L.; Hale, M.W.; Lightman, S.L.; Plotsky, P.M.; Lowry, C.A. Adverse early life experience and social stress during adulthood interact to increase serotonin transporter mRNA expression. Brain Res. 2009, 1305, 47-63. [CrossRef] [PubMed]

22. Tottenham, N.; Galván, A. Stress and the adolescent brain: Amygdala-prefrontal cortex circuitry and ventral striatum as developmental targets. Neurosci. Biobehav. Rev. 2016, 70, 217-227. [CrossRef] [PubMed]

23. Medina, A.C.; Charles, J.R.; Espinoza-González, V.; Sánchez-Resendis, O.; Prado-Alcalá, R.A.; Roozendaal, B.; Quirarte, G.L. Glucocorticoid administration into the dorsal striatum corrected facilitates memory consolidation of inhibitory avoidance training but not of the context or footshock components. Learn. Mem. 2007, 14, 673-677. [CrossRef]

24. Quirarte, G.L.; de La Teja, I.S.L.; Casillas, M.; Serafín, N.; Prado-Alcalá, R.A.; Roozendaal, B. Corticosterone infused into the dorsal striatum selectively enhances memory consolidation of cued water-maze training. Learn. Mem. 2009, 16, 586-589. [CrossRef] [PubMed]

25. Schwabe, L.; Wolf, O.T. Stress modulates the engagement of multiple memory systems in classification learning. J. Neurosci. 2012, 32, 11042-11049. [CrossRef] [PubMed]

26. Siller-Pérez, C.; Fuentes-Ibañez, A.; Sotelo-Barrera, E.L.; Serafín, N.; Prado-Alcalá, R.A.; Campolongo, P.; Roozendaal, B.; Quirarte, G.L. Glucocorticoid interactions with the dorsal striatal endocannabinoid system in regulating inhibitory avoidance memory. Psychoneuroendocrinology 2019, 99, 97-103. [CrossRef] [PubMed]

27. Ono, Y.; Lin, H.-C.; Tzen, K.-Y.; Chen, H.-H.; Yang, P.-F.; Lai, W.-S.; Chen, J.-H.; Onozuka, M.; Yen, C.-T. Active coping with stress suppresses glucose metabolism in the rat hypothalamus. Stress 2012, 15, 207-217. [CrossRef] 
28. Edwards, C.R.W.; Burt, D.; Mcintyre, M.A.; de Kloet, E.R.; Stewart, P.M.; Brett, L.; Sutanto, W.S.; Monder, C. Localisation of $11 \beta$-Hydroxysteroid Dehydrogenase-Tissue Specific Protector of the Mineralocorticoid Receptor. Lancet 1988, 332, 986-989. [CrossRef]

29. Funder, J.W.; Pearce, P.T.; Smith, R.; Smith, A.I. Mineralocorticoid action: Target tissue specificity is enzyme, not receptor, mediated. Science 1988, 242, 583-585. [CrossRef]

30. Goodman, J.; Leong, K.-C.; Packard, M.G. Emotional modulation of multiple memory systems: Implications for the neurobiology of post-traumatic stress disorder. Rev. Neurosci. 2012, 23, 627-643. [CrossRef]

31. Schwabe, L.; Tegenthoff, M.; Höffken, O.; Wolf, O.T. Mineralocorticoid receptor blockade prevents stress-induced modulation of multiple memory systems in the human brain. Biol. Psychiatry 2013, 74, 801-808. [CrossRef] [PubMed]

32. Sinha, R.; Lacadie, C.M.; Constable, R.T.; Seo, D. Dynamic neural activity during stress signals resilient coping. Proc. Natl. Acad. Sci. USA 2016, 113, 8837-8842. [CrossRef] [PubMed]

33. Nikolova, Y.S.; Bogdan, R.; Brigidi, B.D.; Hariri, A.R. Ventral striatum reactivity to reward and recent life stress interact to predict positive affect. Biol. Psychiatry 2012, 72, 157-163. [CrossRef] [PubMed]

34. Corral-Frías, N.S.; Nikolova, Y.S.; Michalski, L.J.; Baranger, D.A.A.; Hariri, A.R.; Bogdan, R. Stress-related anhedonia is associated with ventral striatum reactivity to reward and transdiagnostic psychiatric symptomatology. Psychol. Med. 2015, 45, 2605-2617. [CrossRef]

35. Fareri, D.S.; Tottenham, N. Effects of early life stress on amygdala and striatal development. Dev. Cogn. Neurosci. 2016, 19, 233-247. [CrossRef]

36. Heller, A.S.; Johnstone, T.; Light, S.N.; Peterson, M.J.; Kolden, G.G.; Kalin, N.H.; Davidson, R.J. Relationships between changes in sustained fronto-striatal connectivity and positive affect in major depression resulting from antidepressant treatment. Am. J. Psychiatry 2013, 170, 197-206. [CrossRef]

37. Gatzke-Kopp, L.M.; Beauchaine, T.P.; Shannon, K.E.; Chipman, J.; Fleming, A.P.; Crowell, S.E.; Liang, O.; Johnson, L.C.; Aylward, E. Neurological correlates of reward responding in adolescents with and without externalizing behavior disorders. J. Abnorm. Psychol. 2009, 118, 203-213. [CrossRef]

38. Taghzouti, K.; Lamarque, S.; Kharouby, M.; Simon, H. Interindividual differences in active and passive behaviors in the forced-swimming test: Implications for animal models of psychopathology. Biol. Psychiatry 1999, 45, 750-758. [CrossRef]

39. Jama, A.; Cecchi, M.; Calvo, N.; Watson, S.J.; Akil, H. Inter-individual differences in novelty-seeking behavior in rats predict differential responses to desipramine in the forced swim test. Psychopharmacology 2008, 198, 333-340. [CrossRef]

40. Flores-Serrano, A.G.; Vila-Luna, M.L.; Álvarez-Cervera, F.J.; Heredia-López, F.J.; Góngora-Alfaro, J.L.; Pineda, J.C. Clinical doses of citalopram or reboxetine differentially modulate passive and active behaviors of female Wistar rats with high or low immobility time in the forced swimming test. Pharmacol. Biochem. Behav. 2013, 110, 89-97. [CrossRef]

41. Shin, L.M.; Liberzon, I. The neurocircuitry of fear, stress, and anxiety disorders. Neuropsychopharmacology 2010, 35, 169-191. [CrossRef]

42. Kalin, N.H.; Shelton, S.E.; Rickman, M.; Davidson, R.J. Individual differences in freezing and cortisol in infant and mother rhesus monkeys. Behav. Neurosci. 1998, 112, 251-254. [CrossRef] [PubMed]

43. Núñez, J.F.; Ferré, P.; Escorihuela, R.M.; Tobeña, A.; Fernández-Teruel, A. Effects of Postnatal Handling of Rats on Emotional, HPA-Axis, and Prolactin Reactivity to Novelty and Conflict. Physiol. Behav. 1996, 60, 1355-1359. [CrossRef]

44. Takahashi, L.K.; Rubin, W.W. Corticosteroid induction of threat-induced behavioral inhibition in preweanling rats. Behav. Neurosci. 1993, 107, 860-866. [CrossRef] [PubMed]

45. Avinun, R.; Nevo, A.; Knodt, A.R.; Elliott, M.L.; Radtke, S.R.; Brigidi, B.D.; Hariri, A.R. Reward-Related Ventral Striatum Activity Buffers against the Experience of Depressive Symptoms Associated with Sleep Disturbances. J. Neurosci. 2017, 37, 9724-9729. [CrossRef] [PubMed]

46. Shimojo, M.; Whorwood, C.B.; Stewart, P.M. 11 beta-Hydroxysteroid dehydrogenase in the rat adrenal. J. Mol. Endocrinol. 1996, 17, 121-130. [CrossRef]

47. Kotelevtsev, Y.; Holmes, M.C.; Burchell, A.; Houston, P.M.; Schmoll, D.; Jamieson, P.; Best, R.; Brown, R.; Edwards, C.R.; Seckl, J.R.; et al. 11beta-hydroxysteroid dehydrogenase type 1 knockout mice show attenuated glucocorticoid-inducible responses and resist hyperglycemia on obesity or stress. Proc. Natl. Acad. Sci. USA 1997, 94, 14924-14929. [CrossRef] 
48. Pérez, J.H.; Swanson, R.E.; Lau, H.J.; Cheah, J.; Bishop, V.R.; Snell, K.R.S.; Reid, A.M.A.; Meddle, S.L.; Wingfield, J.C.; Krause, J.S. Tissue-specific expression of $11 \beta-H S D$ and its effects on plasma corticosterone during the stress response. J. Exp. Biol. 2020, 223, jeb209346. [CrossRef]

49. Lecybyl, R.; Jagodzinski, P.P.; Krozowski, Z.S.; Trzeciak, W.H. Regulation of 11beta-hydroxysteroid dehydrogenase type II in rat adrenocortical cells. Endocr. Res. 1998, 24, 643-647. [CrossRef]

50. Estanislau, C. Cues to the usefulness of grooming behavior in the evaluation of anxiety in the elevated plus-maze. Psychol. Neurosci. 2012, 5, 105-112. [CrossRef]

51. Le Moëne, O.; Ågmo, A. The neuroendocrinology of sexual attraction. Front. Neuroendocrinol. 2018, 51, 46-67. [CrossRef] [PubMed]

52. Manukhina, E.B.; Tseilikman, V.E.; Tseilikman, O.B.; Komelkova, M.V.; Kondashevskaya, M.V.; Goryacheva, A.V.; Lapshin, M.S.; Platkovskii, P.O.; Alliluev, A.V.; Downey, H.F. Intermittent hypoxia improves behavioral and adrenal gland dysfunction induced by posttraumatic stress disorder in rats. J. Appl. Physiol. 2018, 125, 931-937. [CrossRef] [PubMed]

53. Kulikov, V.A.; Khotskin, N.V.; Nikitin, S.V.; Lankin, V.S.; Kulikov, A.V.; Trapezov, O.V. Application of 3-D imaging sensor for tracking minipigs in the open field test. J. Neurosci. Methods 2014, 235, 219-225. [CrossRef] [PubMed]

54. Serova, L.I.; Laukova, M.; Alaluf, L.G.; Pucillo, L.; Sabban, E.L. Intranasal neuropeptide Y reverses anxiety and depressive-like behavior impaired by single prolonged stress PTSD model. Eur. Neuropsychopharmacol. 2014, 24, 142-147. [CrossRef]

55. Lapiz-Bluhm, M.D.S.; Bondi, C.O.; Doyen, J.; Rodriguez, G.A.; Bédard-Arana, T.; Morilak, D.A. Behavioural assays to model cognitive and affective dimensions of depression and anxiety in rats. J. Neuroendocrinol. 2008, 20, 1115-1137. [CrossRef]

56. Gruetter, R. Automatic, localized in vivo adjustment of all first- and second-order shim coils. Magn. Reson. Med. 1993, 29, 804-811. [CrossRef]

57. Tkac, I.; Starcuk, Z.; Choi, I.Y.; Gruetter, R. In vivo 1H NMR spectroscopy of rat brain at 1 ms echo time. Magn. Reson. Med. 1999, 41, 649-656. [CrossRef]

58. Provencher, S.W. Estimation of metabolite concentrations from localized in vivo proton NMR spectra. Magn. Reson. Med. 1993, 30, 672-679. [CrossRef]

59. Moshkin, M.P.; Akulov, A.E.; Petrovski, D.V.; Saik, O.V.; Petrovskiy, E.D.; Savelov, A.A.; Koptyug, I.V. Proton magnetic resonance spectroscopy of brain metabolic shifts induced by acute administration of 2-deoxy-d-glucose and lipopolysaccharides. NMR Biomed. 2014, 27, 399-405. [CrossRef]

60. Selyatitskaya, V.G.; Cherkasova, O.P.; Pankina, T.V.; Palchikova, N.A. Functional state of adrenocortical system in rats with manifest alloxan-induced diabetes mellitus. Bull. Exp. Biol. Med. 2008, 146, 708-710. [CrossRef]

61. Bă̌kova, L.A.; Fedorov, V.I.; Cherkasova, O.P. Analiz kortikosteroidov plazmy krovi metodom mikrokolonochnor̆ zhidkostnoı̆ khromatografii. Lab. Delo 1989, 5, 57-60.

62. Baram, G.I.; Grachev, M.A.; Komarova, N.I.; Perelroyzen, M.P.; Bolvanov, Y.A.; Kuzmin, S.V.; Kargaltsev, V.V.; Kuper, E.A. Micro-column liquid chromatography with multi-wave-length photometric detection. J. Chromatogr. A 1983, 264, 69-90. [CrossRef]

(C) 2020 by the authors. Licensee MDPI, Basel, Switzerland. This article is an open access article distributed under the terms and conditions of the Creative Commons Attribution (CC BY) license (http://creativecommons.org/licenses/by/4.0/). 